\title{
Investigation on the dominant key to achieve superior Ge surface passivation by $\mathrm{GeO}_{x}$ based on the ozone oxidation
}

\author{
Jie Zhang, Shuhua Wei, Jing Zhang \\ Microelectronics Department, North China University of Technology, Beijing 100041, China \\ 949135167@qq.com \\ Xiaolei Wang, Wenwu Wang \\ Key Laboratory of Microelectronics Devices \& Integrated Technology, Institute of Microelectronics, \\ Chinese Academy of Sciences, Beijing 100029, China
}

\begin{abstract}
The dominant key to achieve superior Ge surface passivation by $\mathrm{GeO}_{\mathrm{x}}$ interfacial layer is investigated based on ozone oxidation. The interface state density $\left(D_{i t}\right)$ measured from low temperature conduction method is found to decrease with increasing the $\mathrm{GeO}_{\mathrm{x}}$ thickness $(0.26-1.06 \mathrm{~nm})$. The $\mathrm{X}$-ray photoelectron spectroscopy (XPS) is employed to demonstrate the interfacial structure of $\mathrm{GeO}_{\mathrm{x}} / \mathrm{Ge}$ with different $\mathrm{GeO}_{\mathrm{x}}$ thicknesses. And the XPS results show that $\mathrm{Ge}^{3+}$ oxide component is responsible to the decrease of the $D_{i t}$ due to the effective passivation of $\mathrm{Ge}$ dangling bonds. Therefore, the formation of $\mathrm{Ge}^{3+}$ component is the dominant key to achieve low $D_{i t}$ for Ge gate stacks. Our work confirms that the same physical mechanism determines the Ge surface passivation by the $\mathrm{GeO}_{\mathrm{x}}$ regardless of the oxidation methods to grow the $\mathrm{GeO}_{\mathrm{x}}$ interfacial layer. As a result, to explore a growth process that can realize sufficient $\mathrm{Ge}^{3+}$ component in the $\mathrm{GeO}_{\mathrm{x}}$ interlayer as thin as possible is important to achieve both equivalent oxide thickness scaling and superior interfacial property simultaneously. This conclusion is helpful to engineer the optimization of the Ge gate stacks.
\end{abstract}

Keywords-Ge; MOS; XPS; interface trap density; passivation

\section{INTRODUCTION}

Ge channel is a rather potential booster for the future high performance metal-oxide-semiconductor field-effecttransistor (MOSFET) owing to its high carrier mobility [1]. A high quality Ge MOS gate stacks with low interface state density $\left(D_{i t}\right)$ is imperative for the successful industrial application [2]. After about 15 years' intensive studies [3-5], it has been demonstrated that $\mathrm{Ge}$ dioxide or sub-oxide $\left(\mathrm{GeO}_{\mathrm{x}}\right)$ can provide excellent electrical properties with the $D_{i t}$ in the range of $10^{10}-10^{11} \mathrm{~cm}^{-2} \cdot \mathrm{eV}^{-1}$ [6-17]. And the $\mathrm{GeO}_{\mathrm{x}}$ can be grown by thermal oxidation in atmospheric pressure $\mathrm{O}_{2}[\underline{6}$; 7], high pressure $\mathrm{O}_{2}(\sim 70 \mathrm{~atm})[13 ; 14]$, oxygen plasma [9-12; $\underline{17}]$, or ozone oxidation $[\underline{8} ; \underline{15} ; \underline{16}$. Zhang et al. [18] demonstrated that by using the electron cyclotron resonance oxygen plasma post oxidation method, the equivalent oxide thickness (EOT) of the $\mathrm{HfO}_{2} / \mathrm{Al}_{2} \mathrm{O}_{3} / \mathrm{GeO}_{\mathrm{x}} / \mathrm{Ge}$ gate stacks can be scaled down to $0.7-0.8 \mathrm{~nm}$ with maintaining the $\mathrm{D}_{\mathrm{it}}$ in the level of $10^{11} \mathrm{~cm}^{-2} \cdot \mathrm{eV}^{-1}$. Simultaneously, the peak mobilities are 546 and $689 \mathrm{~cm}^{2} / \mathrm{V} \cdot \mathrm{s}$ for the holes and electrons, respectively. Lee et al. [19] reported the postoxidation of $\mathrm{Y}_{2} \mathrm{O}_{3} / \mathrm{Ge}$ structure in high pressure $\mathrm{O}_{2}$ of $\sim 70$ atm at $500{ }^{\circ} \mathrm{C}$. The EOT of $0.94 \mathrm{~nm}$ and $\mathrm{D}_{\mathrm{it}}$ in the level of $10^{11} \mathrm{~cm}^{-2} \cdot \mathrm{eV}^{-1}$ are obtained with the peak electron mobility of $787 \mathrm{~cm}^{2} / \mathrm{V} \cdot \mathrm{s}$. In order to further improve the performance of Ge MOSFET, the EOT should be continually scaling down to about $0.5 \mathrm{~nm}$ while maintaining the low $\mathrm{D}_{\text {it }}$ [20]. Decreasing the $\mathrm{GeO}_{\mathrm{x}}$ thickness is an effective method due to its relatively low permittivity. However, it is found that the $D_{\text {it }}$ increases with decreasing the $\mathrm{GeO}_{\mathrm{x}}$ thickness $[\underline{8} ; \underline{17} ; \underline{18} ; \underline{20} ; \underline{21}]$. Zhang et al. $[18 ; 20 ; 21]$ observed that the $\mathrm{D}_{\text {it }}$ at $0.2 \mathrm{eV}$ below the intrinsic level in Ge increases from 1.7 to $8 \times 10^{11} \mathrm{~cm}^{-2} \cdot \mathrm{eV}^{-1}$ with decreasing the $\mathrm{GeO}_{\mathrm{x}}$ thickness from 1.2 to $0.23 \mathrm{~nm}$ [21]. Furthermore, Shibayama et al. [2] found that this dependence of the $\mathrm{D}_{\mathrm{it}}$ on the $\mathrm{GeO}_{\mathrm{x}}$ thickness can be attributed to the amount of the $\mathrm{Ge}^{3+}$ oxide component at the interface. It should be noted that this $\mathrm{GeO}_{\mathrm{x}}$ thickness dependence of the $D_{i t}$ is experimentally obtained based on the plasma oxidation $[17 ; 18 ; 20 ; 21]$, or post thermal oxidation in the $\mathrm{O}_{2}$ [2]. In addition, Kuzum et al. [8] reported that increasing $\mathrm{GeO}_{\mathrm{x}}$ thickness was beneficial to the $\mathrm{D}_{\text {it }}$ decrease based on the ozone oxidation, and they considered that the $\mathrm{Ge}^{4+}$ oxide component played a dominant role in the $D_{i t}$ passivation. Therefore, the similar experimental results of the $\mathrm{D}_{\text {it }}$ dependence on the $\mathrm{GeO}_{\mathrm{x}}$ thickness are observed for the plasma oxidation, thermal oxidation in $\mathrm{O}_{2}$ and the ozone oxidation, but the passivation mechanisms of the three oxidation methods seem inconsistent, especially for the ozone oxidation. As a result, the passivation mechanism of $\mathrm{GeO}_{\mathrm{x}}$ on the $\mathrm{Ge}$ surface needs further investigation. Especially the ozone oxidation needs further and systematic investigations to clarify whether its passivation mechanism is the same as the plasma or thermal $\mathrm{O}_{2}$ oxidation. The ozone oxidation method is fascinating because it can grow the $\mathrm{GeO}_{\mathrm{x}}$ at low temperature $\left(\sim 300{ }^{\circ} \mathrm{C}\right)$ to avoid the $\mathrm{GeO}_{\mathrm{x}}$ desorption above $\sim 420{ }^{\circ} \mathrm{C}$ [22-24]. In addition, in order to further improve interface properties of $\mathrm{GeO}_{\mathrm{x}} / \mathrm{Ge}$ interface, it is quite important to clarify the dominant factor determining 
the interface properties. Therefore, the comprehensive understandings of the passivation mechanism by the $\mathrm{GeO}_{\mathrm{x}}$ interfacial layer and the relationship between interface structure and electrical properties are necessary. In this paper, the passivation mechanism and dominant key of the $\mathrm{Ge}$ surface passivation by the $\mathrm{GeO}_{\mathrm{x}}$ is systematically investigated by the ozone oxidation method. It is experimentally found that the $\mathrm{D}_{\mathrm{it}}$ decreases with increasing the $\mathrm{GeO}_{\mathrm{x}}$ thickness. The X-ray photoelectron spectroscopy (XPS) characterization shows that the $\mathrm{Ge}^{3+}$ is the dominant factor in determining the electrical properties at the $\mathrm{GeO}_{\mathrm{x}} / \mathrm{Ge}$ interface. Our work indicates that no matter of the oxidation methods to grow the $\mathrm{GeO}_{\mathrm{x}}$ interfacial layer the same physical mechanism determines the Ge surface passivation by the $\mathrm{GeO}_{\mathrm{x}}$.

\section{EXPERIMENTAL}

The Ge based MOS capacitors were fabricated as follows. The starting substrate is 2 m thick p-doped (100) epitaxial Ge on 8 inch p-doped (100) Si. After the cleaning of $\mathrm{Ge}$ surface by 100:1 $\mathrm{H}_{2} \mathrm{O}: \mathrm{HF}$ for $60 \mathrm{~s}$, the wafers were immediately capped with low temperature oxide $\mathrm{SiO}_{2}$. Then active areas were partially opened by lithography-defined wet chemical etching, and the exposed Ge surface was again dipped in 100:1 $\mathrm{H}_{2} \mathrm{O}: \mathrm{HF}$ for $60 \mathrm{~s}$. After that the Ge surface was immediately subjected to $\mathrm{O}_{3}$ surface passivation at 300 ${ }^{\circ} \mathrm{C}$ to form $\mathrm{GeO}_{\mathrm{x}}$. The $\mathrm{O}_{3}$ oxidation time was varied in order to modulate the thickness of the $\mathrm{GeO}_{\mathrm{x}}$ interlayer. Subsequently, $10 \mathrm{~nm} \mathrm{Al}_{2} \mathrm{O}_{3}$ was deposited by atomic layer deposition (ALD) using Trimethylaluminum (TMA) and $\mathrm{H}_{2} \mathrm{O}$ as precursors at $300{ }^{\circ} \mathrm{C}$. Then post deposition annealing (PDA) was performed at $400{ }^{\circ} \mathrm{C}$ in $\mathrm{N}_{2}$ for $5 \mathrm{~min}$, followed by the deposition of the metal gate of $3 \mathrm{~nm} \mathrm{TiN}$ and $75 \mathrm{~nm} \mathrm{~W}$ by the ALD. After that the metal gate was patterned by lithography-defined dry etching. Then $\mathrm{Al}$ electrode was sputtered as backside contact. Finally the wafers were subjected to the forming gas annealing at $400{ }^{\circ} \mathrm{C}$ in $5 \%$ $\mathrm{H}_{2} / 95 \% \quad \mathrm{~N}_{2}$ for $30 \mathrm{~min}$. The capacitance-voltage $(\mathrm{C}-\mathrm{V})$ characteristics were measured by Agilent semiconductor parameter analyzers. The angle resolved X-ray photoelectron spectroscopy (XPS) were recorded using Thermo Scientific ESCALAB 250xi equipped with a monochromatic $\mathrm{Al} \mathrm{K} \alpha$ radiation source. All the high resolution spectra were collected with pass energy of $15 \mathrm{eV}$.

\section{RESULTS AND DISCUSSION}

The electrical properties of the ozone oxidation $\mathrm{W} / \mathrm{TiN} / \mathrm{Al}_{2} \mathrm{O}_{3} / \mathrm{GeO}_{\mathrm{x}} / \mathrm{Ge}$ gate stacks are examined by using MOS capacitors. Figure 1 shows the $\mathrm{C}-\mathrm{V}$ curves of $\mathrm{W} / \mathrm{TiN} / \mathrm{Al}_{2} \mathrm{O}_{3} / \mathrm{GeO}_{\mathrm{x}} / \mathrm{Ge} \mathrm{MOS}$ capacitor at room temperature, which has a $1.06 \mathrm{~nm}$ thick $\mathrm{GeO}_{\mathrm{x}}$. The thickness of $\mathrm{GeO}_{\mathrm{x}}$ is evaluated from the corresponding XPS spectrum. The superior $\mathrm{C}-\mathrm{V}$ characteristics are observed. The kink at the depletion region is attributed to the minority carrier response associated with the small band gap and high intrinsic carrier density of Ge [25; 26]. The conduction method at low temperature was employed to quantitatively evaluate the $D_{\text {it }}$ at $\mathrm{GeO}_{\mathrm{x}} / \mathrm{Ge}$ interface. The energy distributions of the $\mathrm{D}_{\mathrm{it}}$ with different $\mathrm{GeO}_{\mathrm{x}}$ thickness are shown in the inset of Fig. 2. It is clearly observed that the $D_{i t}$ decreases with increasing the $\mathrm{GeO}_{\mathrm{x}}$ thickness. The lowest $\mathrm{D}_{\mathrm{it}}$ detected in the experiments decreases from $6.25 \times 10^{11}$ to $2.06 \times 10^{11} \mathrm{~cm}^{-2} \cdot \mathrm{eV}^{-1}$ when the $\mathrm{GeO}_{\mathrm{x}}$ thickness increases from 0.26 to $1.06 \mathrm{~nm}$. The $\mathrm{D}_{\mathrm{it}}$ at $0.3 \mathrm{eV}$ above the valence band maximum $\left(\mathrm{E}_{\mathrm{v}}\right)$ are compared as a function of the $\mathrm{GeO}_{\mathrm{x}}$ thickness in the Fig. 2. It can be found that, with the $\mathrm{GeO}_{\mathrm{x}}$ thicker than $\sim 0.6 \mathrm{~nm}$, the $\mathrm{D}_{\text {it }}$ varies very slowly as a function of the $\mathrm{GeO}_{\mathrm{x}}$ thickness and reaches a saturation value of $\sim 3 \times 10^{11} \mathrm{~cm}^{-2} \cdot \mathrm{eV}^{-1}$. On the other hand, when the $\mathrm{GeO}_{\mathrm{x}}$ is thinner than $\sim 0.6 \mathrm{~nm}$, the $\mathrm{GeO}_{\mathrm{x}} / \mathrm{Ge}$ interfacial property encounters a drastic degradation with decreasing the $\mathrm{GeO}_{\mathrm{x}}$ thickness. These results indicate that the interfacial property at $\mathrm{GeO}_{\mathrm{x}} / \mathrm{Ge}$ interface is dependent on the $\mathrm{GeO}_{\mathrm{x}}$ thickness, and the $0.6 \mathrm{~nm}$ thick $\mathrm{GeO}_{\mathrm{x}}$ is necessary to realize fine passivation of the Ge surface. As a result, considering the similar results from plasma oxidation and thermal $\mathrm{O}_{2}$ oxidation $[2 ; 18 ; 20 ; 21]$, it is reasonable to conclude that the same passivation mechanism by the $\mathrm{GeO}_{\mathrm{x}}$ appears regardless of the oxidation method such as plasma, thermal $\mathrm{O}_{2}$ or $\mathrm{O}_{3}$ oxidation.

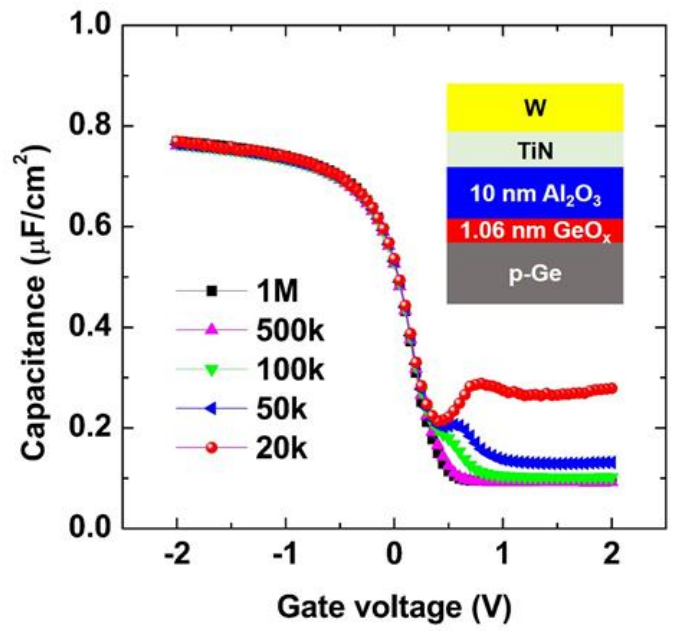

FIG. 1. $\mathrm{C}-\mathrm{V}$ characteristic of the $\mathrm{W} / \mathrm{TiN} / \mathrm{Al}_{2} \mathrm{O}_{3} / \mathrm{GeO}_{\mathrm{x}} / \mathrm{Ge}$ MOS capacitor with $1.06 \mathrm{~nm}$ thick $\mathrm{GeO}_{\mathrm{x}}$. The inset figure is a schematic of the W/TiN/ $\mathrm{Al}_{2} \mathrm{O}_{3} / \mathrm{GeO}_{\mathrm{x}} / \mathrm{Ge} \mathrm{MOS}$ capacitor.

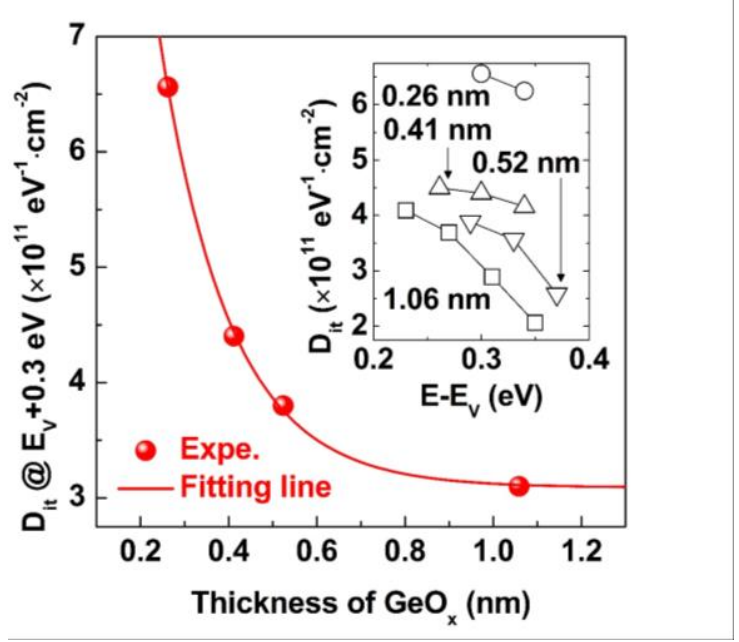

FIG. 2. The $\mathrm{D}_{\text {it }}$ values at $0.3 \mathrm{eV}$ above the $\mathrm{E}_{\mathrm{v}}$ and the energy distributions of the $\mathrm{D}_{\mathrm{it}}$ (inset figure) of the 
W/TiN/ $/ \mathrm{Al}_{2} \mathrm{O}_{3} / \mathrm{GeO}_{\mathrm{x}} / \mathrm{Ge}$ MOS capacitors with different $\mathrm{GeO}_{\mathrm{x}}$ thicknesses.

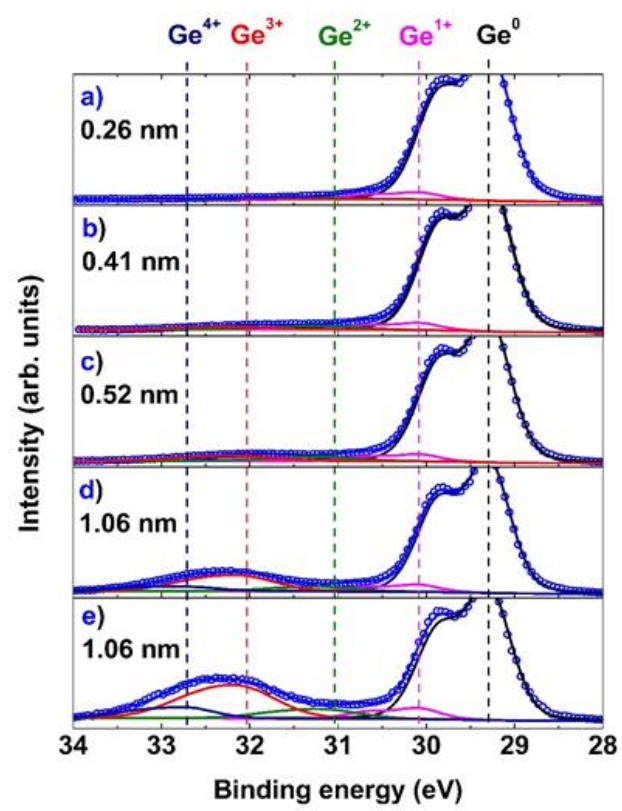

FIG. 3. The XPS spectra of $\mathrm{Ge} 3 d$ for $1 \mathrm{~nm} \mathrm{Al}{ }_{2} \mathrm{O}_{3} / \mathrm{GeO}_{x} / \mathrm{Ge}$ structure with different $\mathrm{GeO}_{\mathrm{x}}$ thicknesses. The thickness of the $\mathrm{GeO}_{\mathrm{x}}$ is shown in the figures. The takeoff angel in the Fig. 3(a)-(d) is $90^{\circ}$ (normal to the sample surface) while that is $35^{\circ}$ in the Fig. 3(e). The Ge $3 d$ line shape is used for the peak fitting and the $\mathrm{Ge} 3 d_{5 / 2-3 / 2}$ doublets are not distinguished in the spectrum deconvolution. The $\mathrm{Ge}^{0}, \mathrm{Ge}^{1+}$, $\mathrm{Ge}^{2+}, \mathrm{Ge}^{3+}$ and $\mathrm{Ge}^{4+}$ shown in the figure mean the binding energies of the Ge $3 d_{5 / 2}$ core level for each chemical state.

In order to physically understand this $\mathrm{GeO}_{\mathrm{x}}$ thickness dependence of the $D_{\text {it }}$ passivation, the XPS technique is employed to characterize the chemical states and composition of each electronic state at the $\mathrm{GeO}_{\mathrm{x}} / \mathrm{Ge}$ interface. Fig. 3 shows the $\mathrm{Ge} 3 d$ spectra of $\mathrm{Al}_{2} \mathrm{O}_{3} / \mathrm{GeO}_{\mathrm{x}} / \mathrm{Ge}$ structure with different $\mathrm{GeO}_{\mathrm{x}}$ thicknesses. It is observed that the peak corresponding to the $\mathrm{GeO}_{\mathrm{x}}$ increases with thicker $\mathrm{GeO}_{\mathrm{x}}$, and the $\mathrm{GeO}_{\mathrm{x}}$ peak energy shifts toward higher binding energy, suggesting that the oxidation state of $\mathrm{Ge}$ and the $\mathrm{GeO}_{\mathrm{x}} / \mathrm{Ge}$ interfacial structure are dependent on the $\mathrm{GeO}_{\mathrm{x}}$ thickness. In order to quantitatively evaluate each oxidation state of the $\mathrm{Ge}$, the Ge $3 d$ spectra are divided by 5 peaks related to Ge substrate $\left(\mathrm{Ge}^{0}\right)$, Ge suboxide $\left(\mathrm{Ge}^{1+}, \mathrm{Ge}^{2+}, \mathrm{Ge}^{3+}\right)$ and $\mathrm{GeO}_{2}$ $\left(\mathrm{Ge}^{4+}\right)$ components as shown in the Fig. 3. It should be noted that the Ge $3 d$ line shape but not the Ge $3 d_{5 / 2}$ and Ge $3 d_{3 / 2}$ doublets for each Ge chemical state is shown in the Fig. 3. And the chemical shifts of $\mathrm{Ge}^{1+}, \mathrm{Ge}^{2+}, \mathrm{Ge}^{3+}$ and $\mathrm{Ge}^{4+}$ relative to the $\mathrm{Ge}^{0}$ are taken as $0.8,1.8,2.75$ and $3.4 \mathrm{eV}$, respectively [27-30]. In addition, the chemical shift of $\mathrm{Ge}^{4+}$ relative to the $\mathrm{Ge}^{0}$ is also confirmed to be $3.4 \mathrm{eV}$ by thicker $\mathrm{GeO}_{2}$ of $\sim 8.2$ $\mathrm{nm}$ (not shown here), which is prepared by thermal oxidation in 1 atm $\mathrm{O}_{2}$ at $550{ }^{\circ} \mathrm{C}$. It should be noted that the thicker $\mathrm{GeO}_{2}$ is grown by thermal oxidation in $\mathrm{O}_{2}$ at $550{ }^{\circ} \mathrm{C}$ but not in $\mathrm{O}_{3}$ at $300{ }^{\circ} \mathrm{C}$. This is because the $\mathrm{GeO}_{\mathrm{x}}$ thicker than 1.06 $\mathrm{nm}$ is experimentally found not to be obtained by using $\mathrm{O}_{3}$ oxidation at $300{ }^{\circ} \mathrm{C}$. The full with at half maximum (FWHM) of the $\mathrm{Ge}$ oxide component $\left(0.84 \mathrm{eV}\right.$ for $\mathrm{Ge}^{2+}, 0.89 \mathrm{eV}$ for $\mathrm{Ge}^{3+}$ and $\mathrm{Ge}^{4+}$ ) increases compared with that of $\mathrm{Ge}^{0}$ component $(0.57 \mathrm{eV})$, which is due to the broadening of the Ge $3 d$ photoemission peaks arising from static disorder in the amorphous $\mathrm{GeO}_{\mathrm{x}}$. In addition, the symmetric GaussianLorentzian sum function was used in the peak fitting and the optimized \%Gaussian-Lorentzian was found to be $18 \%$.

The issue of $\mathrm{Ge}$ atom diffusion into the $\mathrm{Al}_{2} \mathrm{O}_{3}$ layer is discussed as follows. We consider that the $\mathrm{Ge}$ atom diffusion into the $\mathrm{Al}_{2} \mathrm{O}_{3}$ layer is little or negligible in our experiment. This is because the highest process temperature in our experiment is $400{ }^{\circ} \mathrm{C}$. This temperature of $400{ }^{\circ} \mathrm{C}$ is below the $\mathrm{GeO}_{\mathrm{x}}$ desorption temperature of $\sim 420{ }^{0} \mathrm{C}$. In addition, Shibayama et al.[31] found that after a thermal oxidation of $\mathrm{Al}_{2} \mathrm{O}_{3} / \mathrm{Ge}$ structure in $\mathrm{O}_{2}$ at $550{ }^{\circ} \mathrm{C}$, the $\mathrm{Ge}$ atoms diffused into the $\mathrm{Al}_{2} \mathrm{O}_{3}$ film. However, there was no $\mathrm{Ge}$ diffusion at $400{ }^{0} \mathrm{C}$ thermal annealing. As a result, it is reasonable to conclude that the $\mathrm{Ge}$ atom diffusion into the $\mathrm{Al}_{2} \mathrm{O}_{3}$ layer is negligible and consequently not considered. Furthermore, we analyze the $\mathrm{Al} 2 p$ spectra of the four experimental examples to investigate the Ge diffusion into the $\mathrm{Al}_{2} \mathrm{O}_{3}$ (not shown here). Based on the peak fitting, it was found all the $\mathrm{Al} 2 p$ spectra can be fitted with only one chemical state, and the full with at half maximums (FWHM) for the four examples are all $1.47 \mathrm{eV}$. On the other hand, from the Ge $3 d$ spectrum in the Fig. 3(a), it can be obtained that the $\mathrm{GeO}_{\mathrm{x}}$ thickness is only $0.26 \mathrm{~nm}$, which is less than the thickness $0.32 \mathrm{~nm}$ of one monolayer Ge-O-Ge [29]. In addition, there is rather negligible signals from $\mathrm{Ge}^{3+}$ chemical state in Fig. 3(a). Thus it can be concluded that the $\mathrm{Al}_{2} \mathrm{O}_{3} / \mathrm{Ge}$ interface is nearly abrupt and there is no diffusion of $\mathrm{Ge}$ atoms into the $\mathrm{Al}_{2} \mathrm{O}_{3}$. Considering the same FWHM of the $\mathrm{Al} 2 p$ spectra for the four examples, it can be obtained that the $\mathrm{Al}$ chemical states are same for the four examples, i.e., they are both $\mathrm{Al}_{2} \mathrm{O}_{3}$ without $\mathrm{AlGeO}_{\mathrm{x}}$. As a result, based on the above analysis, we are inclined to consider that the Ge atom diffusion into the $\mathrm{Al}_{2} \mathrm{O}_{3}$ layer is negligible and consequently not considered.

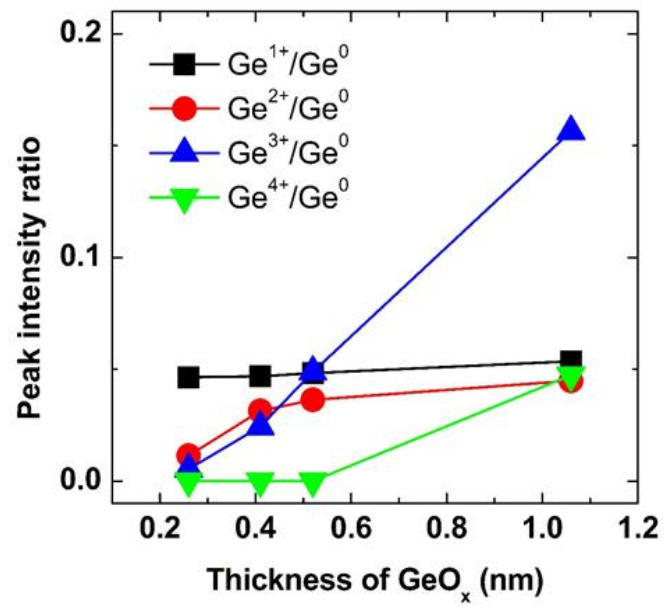

FIG. 4. Area intensity ratios of $\mathrm{Ge}$ oxide components $\left(\mathrm{Ge}^{1+}\right.$, $\mathrm{Ge}^{2+}, \mathrm{Ge}^{3+}$ and $\left.\mathrm{Ge}^{4+}\right)$ to $\mathrm{Ge}^{0}$ component as a function of the $\mathrm{GeO}_{\mathrm{x}}$ thickness.

Figure 4 gives the peak area intensity ratios of $\mathrm{Ge}^{1+}, \mathrm{Ge}^{2+}$, $\mathrm{Ge}^{3+}$ and $\mathrm{Ge}^{4+}$ components to the $\mathrm{Ge}^{0}$ component as a 
function of the $\mathrm{GeO}_{\mathrm{x}}$ thickness. It can be seen that the area intensity ratio of the $\mathrm{Ge}^{1+}$ component is nearly unchanged for different $\mathrm{GeO}_{\mathrm{x}}$ thicknesses, indicating that the $\mathrm{Ge}^{1+}$ component is not responsible for the dependence of the $D_{\text {it }}$ on $\mathrm{GeO}_{\mathrm{x}}$ thickness. The $\mathrm{Ge}^{4+}$ component is not detected by the XPS for the $\mathrm{GeO}_{x}$ thickness of less than $0.52 \mathrm{~nm}$. However there is a significant dependence of the $\mathrm{D}_{\text {it }}$ on $\mathrm{GeO}_{\mathrm{x}}$ thickness in this region. Therefore the $\mathrm{Ge}^{4+}$ component can be ruled out. Similarly the $\mathrm{Ge}^{2+}$ component changes very slowly for the $\mathrm{GeO}_{\mathrm{x}}$ thickness of larger than $0.41 \mathrm{~nm}$, thus it is reasonable to conclude that the $\mathrm{Ge}^{2+}$ component plays a negligible role in passivating the $\mathrm{D}_{\text {it }}$. From the Fig. 4 it can be clearly observed that the $\mathrm{Ge}^{3+}$ component increases significantly with increasing the $\mathrm{GeO}_{\mathrm{x}}$ thickness. In other words, the $\mathrm{D}_{\mathrm{it}}$ decreases with the increment of $\mathrm{Ge}^{3+}$ component, suggesting that the $\mathrm{Ge}^{3+}$ formation is responsible to the $\mathrm{D}_{\text {it }}$ passivation. This conclusion based on the ozone oxidation is consistent with some reports based on the thermal $\mathrm{O}_{2}$ oxidation or plasma oxidation $[2 ; 18 ; 20 ; 21]$. As a result, the passivation mechanism by $\mathrm{GeO}_{\mathrm{x}}$ interlayer is the same regardless of the growth method of $\mathrm{GeO}_{x}$. Based on the above results, the passivation mechanism by $\mathrm{Ge}^{3+}$ component can be understood as follows. Due to the mismatch between the $\mathrm{Ge}$ substrate and $\mathrm{GeO}_{2}$ structure, a transition layer composed of $\mathrm{Ge}^{1+}, \mathrm{Ge}^{2+}$ and $\mathrm{Ge}^{3+}$ components is necessary. Considering that the dangling bonds are the physical origin of the $D_{\text {it }}$ in the Ge gate stacks [34-37], the occurrence of the $\mathrm{Ge}^{3+}$ component is beneficial to decrease the Gibbs free energy of the transition layer and to passivate the dangling bonds of $\mathrm{Ge}$.

\section{CONCLUSIONS}

In summary, the passivation of Ge surface by $\mathrm{GeO}_{x}$ is investigated based on the ozone oxidation. It is experimentally found that the $\mathrm{GeO}_{\mathrm{x}}$ thicker than $0.6 \mathrm{~nm}$ is necessary to achieve fine Ge passivation. And for the $\mathrm{GeO}_{\mathrm{x}}$ thickness thinner than $0.6 \mathrm{~nm}$, the interfacial property degrades dramatically with decreasing the interfacial $\mathrm{GeO}_{\mathrm{x}}$ thickness. These results suggest the trade-off relationship between the EOT scaling and the interfacial quality. This conclusion is verified regardless of the grow method such as plasms, thermal $\mathrm{O}_{2}$ or ozone oxidation. Therefore it can be concluded that the passivation mechanism of Ge surface by $\mathrm{GeO}_{\mathrm{x}}$ interlayer is the same for different $\mathrm{GeO}_{\mathrm{x}}$ growth method. Furthermore, the $\mathrm{D}_{\mathrm{it}}$ at $\mathrm{GeO}_{\mathrm{x}} / \mathrm{Ge}$ interface is clarified to decrease with increasing the amount of $\mathrm{Ge}^{3+}$ state, due to the effective passivation of the Ge dangling bond by $\mathrm{Ge}^{3+}$ component. This indicates that the $\mathrm{Ge}^{3+}$ component is the dominant key to achieve superior Ge surface passivation. As a result, to explore a growth process that can realize sufficient $\mathrm{Ge}^{3+}$ component in the $\mathrm{GeO}_{\mathrm{x}}$ interlayer as thin as possible is important to achieve both EOT scaling and superior interfacial property simultaneously. This conclusion is helpful to the optimization of the Ge based gate stacks for future CMOSFET.

\section{ACKNOWLEDGMENT}

This work was financially supported by National Natural Science Foundation of China (Nos. 61504163, 61574168, 61504001) and the Beijing Municipal Natural Science Foundation (No.4162023).

\section{REFERENCES}

[1] S. Gupta et al., MRS Bulletin 39 (2014) 678-686.

[2] S. Shibayama et al., Thin Solid Films 557 (2014) 282-287.

[3] R.S. Johnson et al., Journal of Vacuum Science \& Technology A 18 (2000) 1230-1233.

[4] C. On Chui et al., IEEE Electron Device Letters 23 (2002) 473 475 .

[5] C.-Y. Su et al., Applied Surface Science 291 (2014) 31-34.

[6] H. Matsubara et al., Applied Physics Letters 93 (2008) 032104.

[7] T. Hosoi et al., Applied Physics Letters 94 (2009) 202112.

[8] D. Kuzum et al., IEEE Electron Device Letters 29 (2008) 328330.

[9] Y. Fukuda et al., Japanese Journal of Applied Physics 44 (2005) 6981-6984.

[10] R. Zhang et al., Applied Physics Letters 98 (2011) 112902.

[11] Q. Xie et al., Applied Physics Letters 97 (2010) 112905

[12] Y. Fukuda et al., IEEE Transactions on Electron Devices 57 (2010) 282-287.

[13] C.H. Lee et al., Applied Physics Express 2 (2009) 071404.

[14] C.H. Lee et al., IEEE Transactions on Electron Devices 58 (2011) 1295-1301.

[15] X. Yang et al., Applied Physics Letters 105 (2014) 092101.

[16] P. Hashemi et al., IEEE Electron Device Letters 33 (2012) 943-945.

[17] M. Kobayashi et al., Journal of Applied Physics 106 (2009) 104117.

[18] R. Zhang, P.-C. Huang, J.-C. Lin, N. Taoka, M. Takenaka, S. Takagi, IEEE Transactions on Electron Devices 60 (2013) 927-934. [19] C.H. Lee et al., 2013 Symposium on VLSI Technology, 2013, T28-T29.

[20] R. Zhang et al., Microelectronic Engineering 88 (2011) 15331536.

[21] R. Zhang, et al., IEEE Transactions on Electron Devices 59 (2012) 335-341.

[22] K. Prabhakaran et al., Applied Physics Letters 76 (2000) 2244-2246.

[23] S.K. Wang et al., Journal of Applied Physics 108 (2010) 054104.

[24] K. Kita et al., A. Toriumi, Japanese Journal of Applied Physics 47 (2008) 2349.

[25] A. Dimoulas et al., Applied Physics Letters 86 (2005) 223507.

[26] K. Martens et al., IEEE Transactions on Electron Devices 55 (2008) 547-556.

[27] S. Sun et al., Applied Physics Letters 89 (2006) 231925

[28] O. Renault et al., Applied Physics Letters 90 (2007) 052112.

[29] K. Kato et al., Japanese Journal of Applied Physics 50 (2011) $10 \mathrm{PE} 02$.

[30] S.K. Sahari et al., Japanese Journal of Applied Physics 50 (2011) 04DA12.

[31] S. Shibayama et al., Thin Solid Films 520 (2012) 3397-3401. 